\title{
Developing Geography Curriculum Framework for Promoting Pre-Service Teachers' Creative Thinking Through Instructional Media Production
}

\author{
Montha Chumsukon ${ }^{1}$ \\ ${ }^{1}$ Faculty of Education, Khon Kaen University, Khon Kaen, Thailand \\ Correspondence: Montha Chumsukon, Faculty of Education, Khon Kaen University, Khon Kaen, Thailand. \\ E-mail: montch@kku.ac.th
}

Received: July 27, 2021

Accepted: August 30, $2021 \quad$ Online Published: September 2, 2021

doi:10.5539/jel.v10n5p197

URL: https://doi.org/10.5539/jel.v10n5p197

\begin{abstract}
The current study explored the effect of a developed Geography curriculum framework towards promoting pre-service teachers' creative thinking (CT) across its 4 components namely: fluency, flexibility, originality, and elaboration through instructional media production. A research and development (R\&D) model were employed which consisted of 3 phases: Phase 1 involved target group survey using a requirement survey form and administered to participants before the study implementation; Phase 2 involved the creation of curriculum and application of the curriculum contents; Phase 3 was the implementation of the curriculum and a mixed-method type of research was employed. 56 participants, organized into 7 groups with 8 members, have participated in 4 sessions of instructional media production. Data were collected from the participants' created instructional media task performance aimed at enhancing their creative thinking. Thereafter, a questionnaire on participants' satisfaction level towards the training as well as interview were conducted after the training was provided. Results revealed that the participants made noteworthy gains as they yielded "high" level on their task performance indicative of an improvement on their CT skills. "Flexibility" and "elaboration" were described as the most and least improved CT components, respectively. Moreover, the participants were most satisfied on the training as most of them revealed that it encouraged them towards effective learning. Additionally, qualitative results reveal participants' positive experiences towards instructional media production which helped foster their CT skills. Finally, the findings have provided substantial support for the instructional media production to be included in the Geography curriculum as an instructional pedagogical support to enhance students' creative thinking skills.
\end{abstract}

Keywords: geography curriculum framework, pre-service teachers, creative thinking, instructional media production

\section{Introduction}

\subsection{Background}

Geography subject has a wide content coverage and are quite challenging to understand and the use of instructional media might help learners to stimulate more of their understanding towards the content, can see pictures and can aid putting them in actual practice and in learning activities which consequently result to a more successful and effective learning and teaching. Instructional media are physical resources an instructor utilizes in his teaching process to facilitate learners' achievement of instructional aims. These resources help improve learners' knowledge, and skills to monitor information that contributes to their improvement. It also aimed at generating a positive behavioural change of an individual (Abimbade, 1997; Owoh, 2016). Oshodi (2014) viewed instructional materials as the vehicle through which teachings are disseminated that appeal to learners' physical senses, so that positive behavioural changes are yielded. Instructional media support learning content that allow students to engage in the application of concepts and thus, offer an opportunity for assessment. They are necessary resources needed to carry out teaching and learning process in order to promote teachers' efficiency and improve students' performance (Ajoke, 2017).

Producing instructional media help inspire learners to keep motivated in learning since it encourages active learning, and therefore, cultivates key critical-thinking skills such as problem-solving and decision-making skills 
(Johnson, Johnson, \& Smith, 2006) creative thinking skills (Eragamreddy, 2013; Runisah et al., 2016) as well as teamwork and collaboration (Dillenbourg, 1999; Lai, 2011). Creative thinking is essential for human life and therefore necessary to be cultivated within the learner. However, despite the pressing demand for creativity, there are fewer curriculums taken into consideration in promoting creative thinking skills (Ritter \& Mostert, 2020). This is true not only in the business world but also in the field of education (Edwards et al., 2006). Hawkins (2001) supported this notion highlighting that we are trained to utilize our knowledge and information; however, are not taught to generate ideas that are novel, valuable, and distinct to other individuals which are indeed necessary requirements to be acquired for the demands of our creative economy.

Creative thinking is an important and necessary skill in the 21 st century that must be developed for learners. Teachers must provide instruction that encourages learners to be thinkers, create knowledge that is linked to the content of Geography subject leading to effective thinking of new things that are beneficial to life and society of their own. Creative thinking can be taught in schools. Research studies have proved that various approaches were linked with such creative process can be demonstrated in the classroom (Ofsted, 2009) and learners' creativity will improve by means of involving them to explore new concepts which will help them solve a challenging task (Runisah et al., 2016). When learners are exposed to such creative activities, it enables them to build stronger scaffolds that eventually enhance them emotionally and intellectually (Cremin, 2009b). This viewpoint is further supported by Runisah et al. (2016) claiming that creative thinking will be heightened if learners are exposed to explore and create unique and valuable ways to a particular problem and are distinctive to other individuals. Thus, teachers must promote learners' creative thinking and develop them to be creative thinkers and creators that can create a creative output leading to real change which is essential to the management of education in the 21 st century (Aree-sophonphichet, 2016). The present study, therefore, attempts to investigate the impact of the Geography curriculum framework being developed to foster pre-service teachers' creative thinking across its four components such as fluency, originality, flexibility and elaboration through instructional media production with the end-in-view of promoting a sense of teamwork, communication and collaboration.

\subsection{Conceptualization of the Study}

The Social Studies Program of the Faculty of Education in Khon Kaen University (KKU) is an institute for the production of professional teachers in the Mekong basin region with a main goal of producing quality teachers possessing academic ability, display proficiency in the field, contribute to the development of community, provide educational services, possess morality, ethics based on teacher's professional principles, and possess desirable characteristics of a teacher-graduate of a society (Faculty of Education, 2017). From the main goal of producing teacher-graduates, the Faculty realizes the importance of building a network of cooperation to prepare and develop the potential of the young generation in the ASEAN community with important skills in the 21st century conforming with ASEAN Community main goals.ASEAN Socio-Cultural Community (ASCC), one of the three pillars of the ASEAN Community, aims to improve the quality of people's lives, to promote sustainable use of resources, including the promotion of the cultural identity of ASEAN that covers culture, youth and education (Wisalaporn et al., 2015; Tungkasamit, 2016). Thailand and the Lao People's Democratic Republic (PDR) are members of the ASEAN community with a long-standing cooperation and relationship based on cultural, traditional and linguistic similarities (Khachornsart et al., 2017). Recognizing the important role and mission of education, educational institutions in each country need to improve their curriculum and learning management methods in order to align with the ASEAN Community regarding learning skills and self-development. Therefore, it requires cooperation, network building and exchange of knowledge among members of regional countries, which is an important mechanism for fostering the development of important skills, and to strengthen cooperation in order to strengthen ASEAN in the world stage. Thus, since 2017, the Social Studies Program, Faculty of Education, KKU, has begun a pilot project to create a network and to develop teachers to the ASEAN community in the area of the Teacher Production Institute in Mekong Basin Region: Thailand and Lao PDR.

Activities that lead to the concept of creating instructional media that are new, modern, and creative, are found necessary for academic exchange activities of teachers and students of Pakse Teachers College in Lao PDR. The preparation of teaching materials should constitute clear specification of the subject/content so as not to waste time in designing and organizing such group endeavors as well as to reduce time spent on such activities. Thus, the researcher used these findings as an initial thinking base in creating a curriculum to produce instructional media in Geography with emphasis on creativity development activities in five different stages such as preparation stage, thinking stage, thinking presentation stage, retrospective stage and application of thinking stage (Suthirat, 2016; Chantaranuwong, 2015) along with teamwork techniques where group members work together in small groups, exchange ideas and collaborate to help each other (Khaemmani, 2017; Slavin, 1995; 
Johnson \& Johnson, 1994). Meanwhile, the researcher has chosen the subject of media production in the curriculum of Geography subject since Thailand and Lao PDR practically have almost similar natural borders, geographical characteristics, climate, natural resources, culture, traditions and languages. Furthermore, the researcher aimed to study the results of the use of the curriculum to promote creativity and creative thinking among pre-service teachers which will eventually lead to a network of professional teachers who have the potential opportunity to create instructional innovations that might help develop the learners in their own country to become knowledgeable and are able to adopt in the world's fast changing trends.

Furthermore, the results from the survey in terms of the needs of organizing activities of teachers and pre-service teachers of the Pakse Teachers College, Lao PDR found that they needed a process of conducting activities that foster ideas for producing instructional materials that are innovative and collaborative to reduce the time spent on individual activities. Thus, the researcher used the results of the study to create a curriculum which consisted of 4 elements such as objectives, subject matters, activities and evaluation (Boonyarattapan, 2015). Conducting the activities in the curriculum is based on the concept of organizing activities to develop pre-service teachers' creative thinking which involved five stages as follow: preparation stage, thinking stage, thinking presentation stage, retrospective stage and application of thinking stage (Suthirat, 2016; Chantaranuwong, 2015). Teamwork techniques are likewise incorporated where the participants work together in small groups, exchange ideas and collaborate each other (Khaemmani, 2017; Slavin, 1995; Johnson \& Johnson, 1994). The implementation of the curriculum activities can be linked to outcomes of the four elements of creative thinking namely: flexibility, fluency, originality and elaboration (Phan-manee, 1997; Munkham, 2004).

\subsection{Importance of Instructional Media Production}

In the literature, instructional media are information carriers designed specifically to fulfil objectives in a teaching and learning situation (Agu \& Onoh, 2011), and assist teachers in the teaching and learning process since these devices help the teacher to make a lesson and so students learn more and thus, learning becomes more effective (Olufunke \& Olusola 2010). These supplementary materials can effectively aid the teacher in theory teaching classroom or in practical teaching evaluation. Adequate resources used in teaching the class would help the teacher to explore his environment and prepare facilities that would improve the learner's' ability to understand a particular concept in their environment and helps stimulate learner's sense of adventure which establishes the power to think creatively and critically. This view is backed up by the study conducted by Ibikunle (2006) claiming that instructional materials when correctly coordinated to learning objectives, learners' characteristic, learning tasks and longer understanding transfer of training can be heightened.

Another study stated that instructional media include all the substantial resources that a teacher can utilize to carry out teaching and direct students' performance (Omenge \& Priscah, 2016). This includes traditional as well technology materials and methods such as computers, DVDs, CD-ROMs, interactive whiteboard, the Internet. Omenge and Priscah described that these media are considered as instruments to carry out the content lessons to the learners towards a successful instruction. Media can be used effectively in formal situation where students can independently work or a teacher is working with other group of students. Adebayo et al. (2020) conducted a comparative study on the impact of instructional media in the teaching and learning process in selected primary schools and underscored that in order to demonstrate certain skills, it calls for adequate knowledge in the use of different methods and techniques of teaching. Furthermore Adebayo et al. (2020) also emphasized that instructional media in the teaching-learning process is highly justified because the teaching of most subjects to the understanding of learners depends largely on the use of instructional media.

According to Ugwu (2014), a special mode of learning exists through imitation, observation and interaction of the learner and instructional materials placed in the learning environment. Creating teaching materials necessitates teamwork. Team working is an effective way to motivate students' interests in learning since it encourages active learning. Active learning cultivates key critical-thinking, communication, problem-solving, and decision-making skills (Johnson, Johnson, \& Smith, 2006). Working in teams means that members need to communicate to each other to come up with a successful and novel product which necessitates creative thinking skills to attain these. If learners are exposed to an opportunity of creating their instructional media, they may develop a sense of teamwork, communication and collaboration and thus, disposed to creative thinking skills and eventually, foster creative thinking.

\subsection{Creative Thinking Skills, Its Importance and Elements}

Creative thinking (CT) is considered as one of the 21 st century key skills that plays a significant part in a daily problem-solving activity of a particular individual (Runco, 1994). It is entwined with thinking outside the box, linking two or more ideas and insights together, generating novel things that are generated from new innovations 
(Academic Committee of Creative Thinking for Value Management, 2012; Chaowakiratipong, 2016). Generally, people need to study the cause of the problem when they are struck with a problem in order to find a suitable solution. This process requires the ability to analyze the situation which includes thinking out of the box and selecting the best solution for that situation (Kanchanachaya, Suwannatthachote, \& Suwanmonkma, 2013). A creative individual endeavour to explore and create novel and useful ways to a particular problem which is distinctive to other individuals. Creativity is a term coined from the Latin term creo which means "to generate" or "to create" (Runco, 1994). This skill is a capability to produce ideas (Mumford et al., 1998) and to create possible answers that are considered genuine and valuable (Sternberg \& Lubart, 1999) which consequently permit us to remain flexible (Ritter \& Mostert, 2020). A cognitively flexible person is able to respond to the unexpected challenges he/she is encountering in his surrounding (Reiter-Palmon et al., 1998) and this should be cultivated in all aspects of social and international areas in general (UNESCO International Bureau of Education, 2014), and curriculum instruction in the field of education in particular, and Social Studies subject is not an exemption to this.

Research studies stated that creative thinking constitutes four elements such as flexibility, fluency, originality, and elaboration (Torrance, 1962; Phan-manee, 1997; Munkham, 2004; Chaowakiratipong, 2016). Flexibility refers to a person's capability to create different sets of ideas, from which he perceives the idea from different perspectives; fluency is a person's ability to quickly generate tons of ideas or explanations to a particular problematic scenario. Originality on the other hand, refers to the tendency to generate ideas which are distinct from other individuals whilst elaboration describes the skill to elaborate an idea by particularly expounding it with related details. Some of the most commonly listed creative traits are describe by Burt (1970) noting down the traits of creativity which composed of fluency, divergent association, receptivity, and insight into a problem's solution. Guilford (1970) defined the abilities of creativity that included fluency, flexibility and originality which come under the general heading of divergent thinking, and also Roger (1970) has remarked that creativity involves the emergence in action of a novel, relational product, which required a relationship to the surroundings, and the product grows out of the uniqueness of the individual and his surroundings.

A study conducted by Eragamreddy (2013) emphasized that creative thinking skills play an important role both in teaching and learning and must be taught to learners which help lead them to new insights, new approaches, fresh perspectives, and entire new ways of understanding and conceiving of things. Since many methods or techniques have been designed to assist individuals in generating original ideas, Eragamreddy claimed that being cognizant with techniques designed to improve creative thinking contributes learners a set of materials to utilize in their learning process.

Students must be taught to be self-learner and to know how to analyze, share their opinions and rational supports, and listen to opinion of others (Kanchanachaya et al., 2013). Teachers must therefore facilitate the role of organizing learning activities which aimed at allowing learners understand, realize and value learning, able to tell themselves what they study for, learn what is useful that can be used to develop their thinking systems and learn to open the world of learning by using various media (Wongsupachainimit et al., 2013) which has been becoming an essential method that is used to promote learners' awareness and interest for taking part in activities, augment learning outcomes (Gerlach \& Ely, 1980) as well as foster creative thinking skills.

As a corollary to the above, the current study, therefore, investigated the effect of the developed Geography curriculum framework for promoting the pre-service teachers' creative thinking skills across four elements such as flexibility, fluency, originality, and elaboration through production and use of instructional media with a view to fostering their sense of teamwork, communication, and collaboration.

\section{Method}

\subsection{Research Methodology}

The current study employed a Research and Development (R\&D) type of research which composed of three phases:

\section{Phase 1: Needs Analysis}

A total of 58 pre-service teachers of Pakse Teachers College, Champasak Province, Lao PDR majoring in History and Geography participated in this phase during the First Semester of the School Year. They were purposively selected to undergo interviews for the purpose of needs analysis. The findings were found that teachers lacked the ability to promote creative thinking by just using traditional teaching approach such as plain lecture method which is teacher-centered approach. Furthermore, the approach does not encourage students to investigate, solve problems and think solutions in diverse ways. Therefore, the pre-service teachers should be 
supported to use new curriculum framework to further improve their creative thinking with the view of developing their sense of collaboration, communication and teamwork through production and use of instruction media.

\section{Phase 2: Development of Curriculum Framework for Geography}

This phase was on the creation of curriculum where five experts in Social Studies teaching and Curriculum Development were involved. The purpose of this phase proceeded on activities to analyze and integrate the information from the first phase and knowledge concerned about conceptualizing curriculum framework for improving creative thinking through production and use of instructional materials which were created based on Taba (1962) and Boonyaratpan's (2015) curriculums in terms of objectives, subject matter, activities and evaluation. The employed model for enhancing creative thinking of pre-service teachers constituted of five stages as: 1) preparation stage 2) thinking stage, 3) presentation stage 4) retrospective stage 5) application of thinking stage. These stages were carried out through group process composed of problem-solving strategy, communication and collaborative approach and teamwork. Figure 1 presents the curriculum framework designed for Geography subject to develop pre-service teachers' creative thinking through instructional media production.

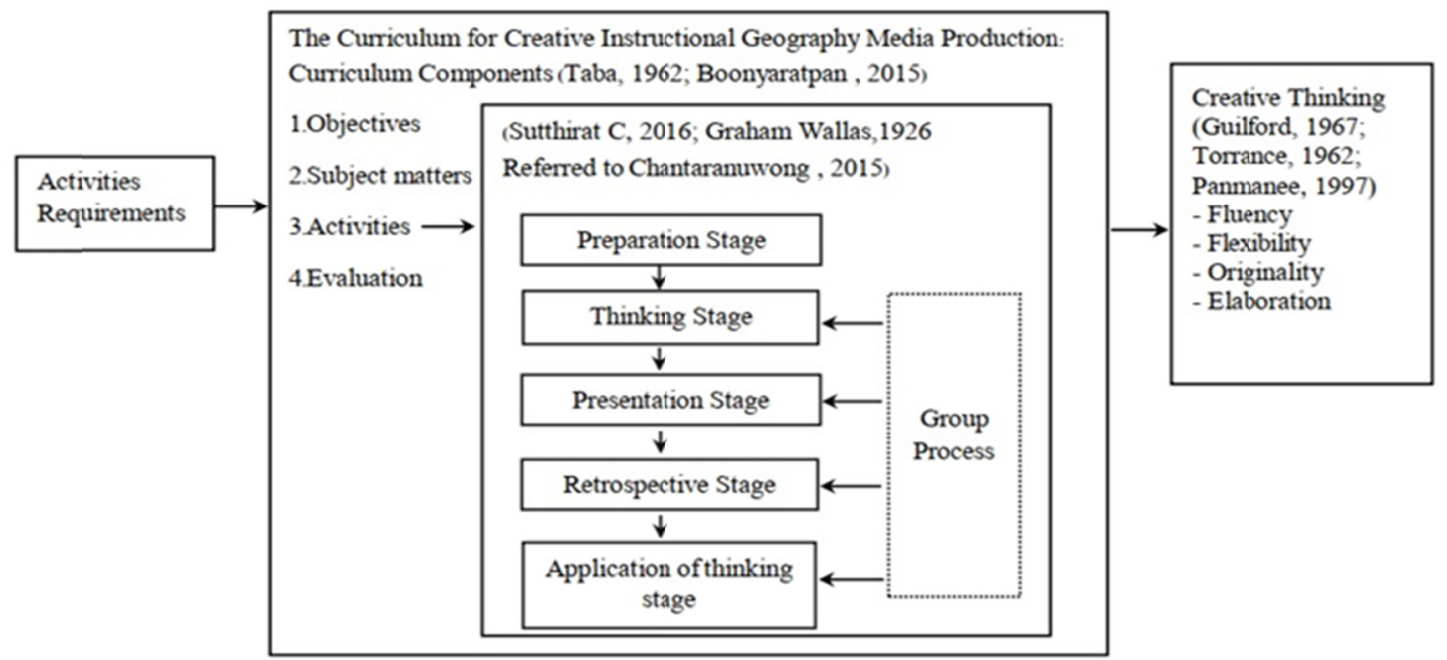

Figure 1. The Geography Curriculum Framework for the development of pre-service teachers' creative thinking through instructional media production

\section{Phase 3: Implementation and Evaluation}

Phase Three focused on the implementation of the curriculum. Here, the mixed-mode method type of research was employed. The 56 purposively selected participants underwent four sessions of training/workshop that concerns instructional media production during the second semester of the School Year. In these workshops, the activities were implemented within the five stages namely: preparation stage, thinking stage, thinking presentation stage, retrospective stage, and application of thinking stage. Each of the seven groups was assigned to create instructional media and was tasked to present the created task orally. Furthermore, the evaluator (the researcher herself roams around to assess the seven groups' works. Thereafter, the creative thinking assessment form across four components of creative thinking such as flexibility, fluency, originality, and elaboration were administered to the participants. The Creative Thinking Assessment form adopted from Srisa-ard (2010) constituted of four component areas namely: fluency, flexibility, originality, and elaboration were used to evaluate the participants' instructional media task performance. This assessment form has a 5-level estimation scale which are as follows: $5=$ most creative level, $4=$ very creative level, $3=$ moderate level, $2=1$ low level, and $1=$ least level of creativity. Finally, the participants underwent interviews using semi-structured type of interviews after the training/workshop was provided on them.

\subsection{Research Instruments}

\subsubsection{Requirement Survey Form}

This tool was used during the first phase to survey the need for training activities and was consisted of five open-ended questionnaires. The tool was created through the following objectives: (1) study the concepts, data, 
and principles related to social studies teaching media production activities; (2) establish a conceptual to explore the needs; (3) create a demand survey that consists of five open-ended questionnaire; (4) present the survey to the three experts for content validity and appropriateness of the language expressions; (5) survey revision based on experts' suggestions; and (6) application of the survey to the target group of Pakse pre-service teachers.

\subsubsection{Creative Thinking Assessment Form}

This form was used during the third phase to assess the participants' instructional media task performance during the training. The creative thinking assessment form was composed of four components of creative thinking such as flexibility, fluency, originality, and elaboration. This form which is based from Srisa-ard (2010) has a 5-level estimation scale as: $5=$ most creative level, $4=$ very creative level, $3=$ moderate level, $2=$ low level, and $1=$ least level of creativity.

\subsubsection{Criterion Scale for Creative Thinking Levels}

This tool was used during the third phase to assess the creative thinking level of the participants and are based on the following criteria adapted from Srisa-ard (2010). The criteria are described from very high level (4.51-5.00) meaning the creative thinking level of the participants is described as the most creative to a very low level (1.00-1.51) which indicates that the creative thinking level of the participants is least creative.

\subsubsection{Questionnaire on Learners' Satisfaction Level Towards the Training}

This tool was used during the third phase and was administered to the participants after the training was provided on them. The purpose of this questionnaire is to study the satisfaction level of the Pakse pre-service teachers towards organizing the training activities on instructional media production. This questionnaire was presented to three experts to consider the content validity and the appropriateness of the language expressions used. Thereafter, it was revised according to the recommendations of experts. The questionnaire was piloted to 30 fourth-year students who were not the research target group. The reliability was analyzed by a reliability value of 0.83 . The questionnaire constitutes of a 10 -item satisfaction questionnaire with 5 satisfaction levels from $5=$ most satisfied to $1=$ least satisfied.

\subsection{Treatment}

The researcher carried out four sessions of organizing the training/workshop. Table 1 presents the plan of activities for creative teaching media production that composed of 4 training sessions with a total of 12 hours together with its corresponding stages and Creative thinking skills being enhanced.

Table 1. Plan of activities for creative teaching media production

\begin{tabular}{|c|c|c|c|c|}
\hline Session/s & $\begin{array}{l}\text { No. of } \\
\text { Hours }\end{array}$ & Activities & Stage/s & $\begin{array}{l}\text { Creative Thinking } \\
\text { Skills }\end{array}$ \\
\hline $\begin{array}{l}\text { Session } \\
1\end{array}$ & 3 hours & $\begin{array}{l}\text {-Getting to know activities to build familiarity. } \\
\text {-Description and demonstration on how to produce creative } \\
\text { instructional media in Geography subject. } \\
\text {-Question and Answer for clarification and check understanding }\end{array}$ & Preparation Stage & $\begin{array}{l}\text {-Fluency } \\
\text {-Flexibility }\end{array}$ \\
\hline $\begin{array}{l}\text { Sessions } \\
2 \text { and } 3\end{array}$ & 5 hours & $\begin{array}{l}\text {-Division of participants into } 7 \text { groups. } \\
\text {-Each group helps each other to design and create instructional } \\
\text { media in Geography subject. }\end{array}$ & Thinking Stage & $\begin{array}{l}\text {-Fluency } \\
\text {-Flexibility } \\
\text {-Originality }\end{array}$ \\
\hline \multirow[t]{3}{*}{$\begin{array}{l}\text { Session } \\
4\end{array}$} & 1 hour & $\begin{array}{l}\text {-Each group presents their created teaching media. } \\
\text {-Other groups jointly critiqued the group's task performance and } \\
\text { suggested improvements. }\end{array}$ & $\begin{array}{l}\text { Thinking } \\
\text { Presentation Stage }\end{array}$ & $\begin{array}{l}\text {-Fluency } \\
\text {-Originality } \\
\text {-Flexibility } \\
\text {-Elaboration }\end{array}$ \\
\hline & 2 hours & $\begin{array}{l}\text {-After the presentation of the created instructional media, each } \\
\text { group considered improving the instructional media based on } \\
\text { the received recommendations from the other groups. }\end{array}$ & $\begin{array}{l}\text { Retrospective } \\
\text { Stage }\end{array}$ & $\begin{array}{l}\text {-Elaboration } \\
\text {-Flexibility }\end{array}$ \\
\hline & 1 hour & $\begin{array}{l}\text {-Each group offered guidelines for applying geography } \\
\text { instructional media to their own teaching and learning } \\
\text { management. }\end{array}$ & $\begin{array}{l}\text { Application of } \\
\text { Thinking stage }\end{array}$ & $\begin{array}{l}\text {-Fluency } \\
\text {-Originality } \\
\text {-Flexibility } \\
\text {-Elaboration }\end{array}$ \\
\hline
\end{tabular}




\subsection{Data Collection}

\subsubsection{Instructional Media Production Task Performance}

This refers to the participants' oral presentation performance regarding the instructional media they created. The participants were grouped into seven with around 8 members. Each group was given time to create one instructional media. Within the group process, various stages such as preparation stage, thinking stage, thinking-presentation stage, retrospective stage, and application of thinking stage, were observed. The observer-researcher took notes of these activities from the participants and were given marks using the creative thinking assessment form which contains four components such as fluency, flexibility, originality, and elaboration constituting of a 5-level estimation scales from 5 (most creative level of creativity) to 1 (least level of creativity).

\subsubsection{Questionnaire on Learners' Satisfaction Level Towards the Training}

This tool was used during the third phase and was administered to the participants after the training was provided on them. The purpose of this questionnaire is to evaluate the satisfaction level of the Pakse pre-service teachers towards the training activities on instructional media production. The questionnaire constitutes of a 10 -item satisfaction questionnaire with 5 satisfaction levels as presented in Table 2.

Table 2. Five satisfaction levels and its description

\begin{tabular}{ll}
\hline Level $/ \mathrm{s}$ & Description \\
\hline $4.51-5.00$ & Most satisfied \\
$3.51-4.50$ & Very Satisfied \\
$2.51-3.50$ & Moderately satisfied \\
$1.51-2.50$ & Less satisfied \\
$1.00-1.50$ & Least satisfied \\
\hline
\end{tabular}

\subsubsection{Interviews}

This is used to gather more details about how the training/workshops would assist the respondents to create instructional media as well as how their creative thinking skills were enhanced. The respondents underwent interviews voluntarily using semi-structured interviews with pre-determined questions. Each of the respondents was given at least 15 minutes to respond to the questions posed by the researcher.

\subsection{Data Analysis}

Data were analyzed by using descriptive statistics such as Mean and Standard Deviation. Moreover, the creative thinking level was assessed according to the following criteria adapted from Srisa-ard (2010). The criteria are described from very high level (4.51-5.00) meaning the creative thinking level of the participants is described as the most creative to a very low level (1.00-1.51) which indicates that the creative thinking level of the participants is least creative. Table 3 below presents the criterion scale for creative thinking levels.

Table 3. Criterion scale for creative thinking levels

\begin{tabular}{ll}
\hline Score & Description \\
\hline $4.51-5.00$ & Very high level \\
$3.51-4.50$ & High level \\
$2.51-3.50$ & Medium level \\
$1.51-2.50$ & Low level \\
$1.00-1.50$ & Very low level \\
\hline
\end{tabular}

Data from questions in the interview protocol were subjected to frequency counts and were analysed using the process of thematic coding (Cresswell, 2008). Table 4 presents the following themes that were emerged after analysis of the participants' responses. 
Table 4. Emerged themes

\begin{tabular}{ll}
\hline Theme/s & Sub-Themes \\
\hline Experiences and benefits they obtained from instructional & - teamwork \\
media production & - creative techniques and methods \\
& - creating more new and novel instructional media \\
Suitability of Instructional media Production & - appropriateness of content, timing, and duration \\
Enhancement of creative thinking & - flexibility \\
& - fluency \\
& - originality \\
& - elaboration \\
\hline
\end{tabular}

\section{Results}

\subsection{Quantitative Analysis}

\subsubsection{Evaluation Results of Pre-Service Teachers' Instructional Media Production Task Performance}

The results from the application of the curriculum in terms of the four components of creative thinking for pre-service teachers majoring in teaching Geography and History subjects at Pakse Teachers College, Lao PDR revealed that the pre-service teachers after the training was implemented, gained overall results described as "high" with Mean and S.D. results of 3.86) and 0.35, respectively. When considering the four creative elements, sorted by average, the pre-service teachers yielded the highest score on the "flexibility" component with $\overline{\mathrm{x}}=4.14$ and S.D. $=0.35$ followed by components on originality $(\overline{\mathrm{x}}=4.00$, S.D. $=0.76)$, fluency $(\overline{\mathrm{x}}=3.86, \mathrm{~S} . \mathrm{D} .=0.64)$ and elaboration $(\overline{\mathrm{x}}=3.43, \mathrm{~S} . \mathrm{D} .=0.49)$ which yielded the least average. The result is shown in Table 5.

Table 5. Evaluation results of pre-service teachers' instructional media production task performance across 4 elements of creative thinking after the training was provided on them

\begin{tabular}{lllllll}
\hline \multirow{2}{*}{ Group/s } & \multicolumn{2}{l}{ Components of Creative Thinking } & \multicolumn{2}{l}{$\begin{array}{l}\text { Overall } \\
\text { Mean }\end{array}$} & Description \\
\cline { 2 - 6 } & Fluency & Flexibility & Originality & Elaboration & 4.00 & High \\
\hline 1 & 4.0 & 4.0 & 4.0 & 4.0 & 3.75 & High \\
2 & 4.0 & 4.0 & 4.0 & 3.0 & 4.50 & High \\
3 & 5.0 & 4.0 & 5.0 & 4.0 & 3.75 & High \\
4 & 3.0 & 4.0 & 5.0 & 3.0 & 4.00 & High \\
5 & 4.0 & 5.0 & 3.0 & 4.0 & 3.50 & Medium \\
6 & 4.0 & 4.0 & 3.0 & 3.0 & 3.50 & Medium \\
7 & 3.0 & 4.0 & 4.0 & 3.0 & 3.86 & \\
Overall Mean & 3.86 & 4.14 & 4.0 & 3.43 & 0.35 & \\
S.D. & 0.64 & 0.35 & 0.76 & 0.49 & & \\
\hline
\end{tabular}

3.1.2 Evaluation Results of the Satisfaction Level of Pakse Pre-Service Teachers Towards the Training Activities on Instructional Materials Production

Table 6 presents the evaluation results of the satisfaction level of Pakse pre-service teachers towards organizing training activities for the production of teaching materials. It is noticeable from the table that overall evaluation results were at a high level gaining an overall Mean of 3.89 and an S.D of 0.48. Of the 10 items, item \# 6 revealed that the participants were most satisfied to the training provided on them yielding a mean score of 4.53 and S.D of 0.82. They revealed that the training is fun, encourage learning towards creation of teaching materials. However, participants were moderately satisfied on item \# 9 with a Mean score of 3.26 and S.D of 0.78 . They indicate that the duration of the activity is appropriate, however, need to allocate a longer duration towards a more successful training. Meanwhile, the participants were very satisfied to the rest of the items $(1,2,3,4,5,7$, 8 , and 10 yielding mean scores and S.D of of $\mathrm{x}=3.88, \mathrm{~S} . \mathrm{D}=0.86 ; \mathrm{x}=4.00, \mathrm{~S} . \mathrm{D}=0.65 ; \mathrm{x}=3.97, \mathrm{~S} . \mathrm{D}=0.70 ; \mathrm{x}=3.78$, $\mathrm{S} . \mathrm{D}=0.88 ; \mathrm{x}=4.19, \mathrm{~S} . \mathrm{D}=0.76 ; \mathrm{x}=4.0, \mathrm{~S} . \mathrm{D}=0.83 ; \mathrm{x}=3.72, \mathrm{~S} . \mathrm{D}=0.74$; and $\mathrm{x}=3.60, \mathrm{~S} . \mathrm{D}=0.67$, respectively. 
Table 6. Evaluation results of the satisfaction level of Pakse pre-service teachers towards the training activities on instructional materials production after the training was provided on them

\begin{tabular}{lllll}
\hline No. & Items & X & S.D. & satisfaction level \\
\hline 1 & The process of organizing activities stimulates creativity. & 3.88 & 0.86 & Very satisfied \\
2 & Encourage exchange of knowledge, opinions, learn together, work in groups. & 4.00 & 0.65 & Very satisfied \\
3 & Teaching materials are diverse, interesting, and creative. & 3.97 & 0.70 & Very satisfied \\
4 & The materials used to make the media are suitable. & 3.78 & 0.88 & Very satisfied \\
5 & The media is suitable to use in teaching/learning social studies subject. & 4.19 & 0.76 & Very satisfied \\
6 & The training is fun, encourage learning towards creation of teaching materials. & 4.53 & 0.82 & Most satisfied \\
7 & The process of transferring knowledge and explaining the process of making media of & 4.00 & 0.82 & Very satisfied \\
& the speakers is logical and clear. & & \\
8 & After receiving the training, knowledge of social studies teaching media has been & 3.72 & 0.74 & Very satisfied \\
& improved/increased. & 3.26 & 0.78 & Moderately satisfied \\
9 & The duration of the activity is appropriate. & 3.60 & 0.67 & Very satisfied \\
10 & Be able to apply the gained knowledge to develop our own teaching. & 3.89 & 0.48 & Very satisfied \\
Total & & &
\end{tabular}

\subsection{Qualitative Analysis}

\subsubsection{Experiences and Benefits They Obtained from Instructional Media Production}

There were 10 respondents (R) participated from the initial stage involved in the interviews. The results revealed that participants could be able to develop their knowledge and foster collaboration during the creation of instructional hand-made media. R2, R4 and R7 expressed their opinions on the benefits they obtained from the workshops:

"The activity on the creation of hand-made media is beneficial to us because it helped us know how to organize group activities and create teaching materials both in group and individual which is very necessary towards students' learning. " $\mathbf{R} 2$.

"Since the activities make us collaborate with peers and friends, apart from exchanging each other's cultures, it also helped us to obtain creative techniques and methods of media production that we do not know before which is very useful to apply them in the real classroom." $\mathbf{R} 4$

"I have gained three good things after undergoing the sessions of workshops: firstly, I have acquired good experiences; secondly, I have got full understanding regarding the preparation of teaching and making media in groups. Finally, I yielded the creative training process of creating more new and novel instructional media which I can use in the future." $\mathbf{R} 7$

R9 expressed her positive opinion regarding the application of knowledge she gained from participating in the workshop and R5 had opinion verbatim transcripts to the former.

"Of course, after the workshop, I myself can use it and be able to impart my knowledge to others. Moreover, the workshop had brought me ample knowledge on how to produce teaching materials that correspond to classroom needs and level of content being taught." $\mathbf{R 9}$

"With the knowledge I gained from the training/workshop, I may be able to apply it by designing handicraft materials that are suitable and appropriate to the content I will teach and to the age level of the students. Furthermore, the hand-made media can aid stimulate students' interests more than lecturing in the classroom." R5

\subsubsection{Suitability of Instructional Media Production}

Since the instructional media production underwent careful curriculum planning and development, most participants enjoyed the activities in the training and workshop. The goal is both to provide plenty of "hands-on" practice and plenty of team working during the implementation. R3 and R6 felt motivated in doing those various activities and viewed that the workshop on instructional media production is so appropriate and suitable for the curriculum since it does not only assist learners to create teaching materials but will eventually enhance creative thinking.

"I think the workshop on media production for a Geography curriculum is very appropriate because it suits to both in content, process and duration. Even though the workshop was implemented in a short period of time, it was carried out successfully since it used orderly procedures and stages, proper timing, and enough appropriate activities." R3

"I believe that the content is just right and appropriate because the creation of teaching materials can not 
only can be used in one situation but in a variety of activities that are deliberately done which attracted our attention." R6

\subsubsection{Enhancement of Creative Thinking}

The results revealed that majority of the participants enhanced their creative thinking as the training and workshop on teaching media production enables them to become more original, flexible, elaborative, and fluent. To illustrate: one element of creative thinking is flexibility which refers to a person's capability to create different sets of ideas, from which he perceives the idea from different perspectives. R9 showed her being flexible as she was able to create different sets of ideas from which she perceives the idea from different perspectives.

"The training/workshop on instructional media production aided me to improve my creative thinking skill especially on becoming a flexible learner. The activity assisted us think of a unique outcome yet plausible. This made us create reasons that something has occurred. Even though problems happened while creating teaching materials, we did not lose focus, instead we attempted as many times as we can until we come up with one successful outcome." R9

Fluency refers to a person's ability to quickly generate tons of ideas or explanations to a particular problematic scenario. R1 exposed her disposition to this element of creative thinking as it assists her to use various ideas or explanations to come up with a particular idea after the training was provided on her.

"When we were given the training and workshop, it helped me practice thinking flexibly by thinking outside the box. I mean from a "yes" or "no" answer to "aha" answer with more details to follow. What I mean is I tried to come up as many ideas as I could from the situation and come up with one complete idea. Furthermore, I was also given the chance to share it during the process of teamworking." R1

Another element of creative thinking is originality refers to the learner's tendency to generate ideas which are different from other learners. Often it is a someone's spontaneous originality that makes us call him "creative." R8 unveiled her opinion regarding this element after given the training.

"The training/workshop given to us was implemented with teamwork activities. During the activities, we first brainstorm, Brainstorming made us become vocal of our ideas and thoughts and these thoughts may either be original or not. Often, my friends share their original ideas regarding the topic of the session. These group activities aided us to share our original ideas and insights to our peers. And this way helped enhance my positive attitude towards learning." $\mathbf{R 8}$

Meanwhile, the last element of creative thinking is elaboration. This element refers to the skill that helps elaborate an idea by particularly explaining and expounding it with detail that relate to each other. To be able to embellish an idea by adding some details to it adds value and create more interesting ideas. R2 expressed her insights regarding this after the training was implemented.

"The training/workshop on instructional media creation developed my skill of elaboration because I was able to develop a concept by adding new options that build interest in the idea and create better understanding of it." R2

The above qualitative results from the interviews yielded remarkable results not only on learners' assessment of their creative thinking levels after the training and workshop was provided on them but also demonstrated an increase on their creative thinking skills and dispositions. Engaging students' interest in the nature of the teaching materials through working on them in some ways like teaching media production, a greater degree of commitment and sense of purposeful activity will be generated.

\section{Discussion}

The findings of the current study after the participants were provided with the training/workshop on instructional media production revealed that the overall creative thinking level of pre-service teachers of Pakse Teachers College, Lao PDR, was at "high level" with Mean and Standard Deviation of 3.86 and 0.35 , respectively. This finding simply manifests that the participants made significant gains in enhancing their creative thinking through production of instructional media. The result was backed-up by the study conducted by Bilda et al. (2007) highlighting that creativity is enhanced when learners are focused and motivated to activities they are enjoying doing. It is true that creativity is manifested when the learners learn to regulate himself to an unexpected situation during an activity he is engaged in. Ritter et al. (2020) claimed that creative thinking constituted of learners who try to put their ideas into practice especially in a particular situation and attempt to visualize the situation into a new insight that can lead them to the identification of alternatives and other explanations, 
connections and links which consequently generate novel outcomes. In the current study, during the preparation stage of instructional media production, the instructor first prepared the participants' atmosphere, body, and mind to stimulate their readiness and further links to the thinking practice where participants can think creatively through instructional media design activities, review and reflect on what have they accomplished and identify the gained benefits from cognition and in conducting group activities. Students yield a higher level of creativity after developing their creative skills by using patterns, techniques for learning management activities (Panya-sai, 2016; Booncherdchoo, 2016). The participants in the current study, when asked during the interview, responded that they were motivated to think creatively when they were provided with the training and workshops. The activities assisted them to flexibly form new insights, original approaches, fresh perspectives, and new ways of understanding things. Creative thinking activities helped learners to discover possibilities that may aid them to construct theories and apply the intuition into practice (Ritter et al., 2020). Thus, forming something that is creative, original, and novel.

In the current study, results disclosed that "flexibility" which is one component of creative thinking yielded the highest average score $(\overline{\mathrm{x}}=4.14$; S.D. $=0.35)$. The study findings could be attributed to the fact that the activities on instructional media production designed in the curriculum helped enhanced the participants' flexibility. The participants have manifested to augment their capability to create different sets of ideas from which they perceived the ideas from different perspectives. Thus, they tend to display regulation through coming up with more ideas after re-evaluating and re-examining the unanticipated situations. Robillos (2020) noted that self-regulated learners can establish goals for their learning, can monitor, can assess and can self-reflect their learning. Creativity may be enhanced when a learner recognizes how to withstand his track to an unanticipated situation during the activity since he is given opportunities to develop and elaborate the activity he is asked to accomplish (Bilda, Edmonds, \& Candy, 2008). They (Bilda, Edmonds, \& Candy, 2008) emphasized that learners, since they have expectations from the activities may get stressed with unexpected situations but can manage to be flexible because of their ability to start believing in it along with new expectations. The ability to reframe conditions is considered one important criterion in measuring creativity. In the present study, the participants have demonstrated flexibility which aided them to transform their stress and worries to "fun and enjoyment" while undertaking the activities. This might be due to the teamwork and collaboration techniques that were incorporated in the activities where the participants work together in small groups, exchange ideas and collaborate each other towards a successful and creative output. Collaboration is a joint engagement done by participants in a coordinated effort to unravel a challenge together (Dillenbourg, 1999). Learning activities jointly done allow learners to provide explanations of their insights that help students reform their views (Van Boxtel, et al., 2000). Furthermore, Lai (2011) claimed that social interaction amplifies one's knowledge as members of the group try to make effort to be understood by other members through discussions that eventually lead them to exchange information arriving at collaborative understanding and conclusion.

Elaboration is one component of creative thinking where it assesses learners' ability to improve, rework, and embellish ideas. Furthermore, this component allows students to "fill in" or add to information to expand on an idea by embellishing it with details. However, the study findings revealed that the least creative thinking component was from "elaboration" ( $(\mathrm{x}=3.43$; S.D. $=0.49)$. The mean score regarding this component yielded the lowest score and this could be due to the fact that pre-service teachers still need to think of what and which ideas and information they would use during the activities. They tend to be reserved in embellishing their ideas and details because they feel unconfident to how they voice their ideas out. They also tend not to elaborate much because they are afraid of the "quality" of ideas they are using. These ideas may either be incorrect or irrelevant. This is in line with the study conducted by Wannapin (2012) reporting that the learners need to use more time in thinking of their ideas to share to their peers and need to be so careful for them to be able to apply those insights and ideas with quality in all aspects. Furthermore, time constraints could also be one of the factors. Since they were only given limited hours to finish the activities, they were unable to improve, rework and add information to expand their idea with more details. This view is further backed up by Phanmanee (2014) emphasizing that it may take time to develop elaborate thinking which will be gently developed by training and ample correct practices.

\section{Conclusion}

Creative Thinking is an essential skill in the 21 st century that needs to be developed to the learner. It is vital for the teachers to focus and develop creative thinking to every individual learner in the classroom. The Geography curriculum framework being developed helped enhance pre-service teachers' creative thinking through production and use of instructional media. It emphasized on the process of organizing activities to be able to promote creativity by focusing on group collaboration and participation to promote thinking processes and 
further create new insights. It helps link the knowledge to action and creates concrete results. This will lead to the development of learners in their own respective places to be critical and creative thinkers that can further change global social context.

\section{References}

Abimbade, A. (1997). Principles and Practice of Educational Technology. Ibadan Josconif.

Academic Committee of Creative Thinking for Value Management. (2012). Creativity for Value Management. Bangkok: Kasetsart University Press.

Adebayo, A., \& Enejo, L. (2020). A Comparative study of the impact of instructional media in the teaching and learning process in selected primary schools in Kogi State. Journal of Contemporary Educational Research, $2(1), 1$.

Agu, I., \& Onoh, I. (2011). Fundamentals of Educational Technology. Awka: Okosis I Press Ltd.

Ajoke, A. R. (2017). The importance of instructional materials in teaching English as a second language. International Journal of Humanities and Social Science Invention, 6(9), 36-44.

Aree-sophonphichet, S. (2016). How to teach and create Creative Thinking. Bangkok: Chulalongkorn University Press.

Bilda, Z., Candy, L., \& Edmonds, E. A. (2007). An embodied cognition framework for interactive experience. Co Design, 3(2), 123-137. https://doi.org/10.1080/15710880701251443

Bilda, Z., Edmonds, E. A., \& Candy, L. (2008). Designing for creative engagement. Design Studies, 29, 525-540. https://doi.org/10.1016/j.destud.2008.07.009

Booncherdchoo, S. L. (2016). The development of creative thinking ability of undergraduate students in early childhood education program through self-regulation learning process approach. Veridian E-Journal Silpakorn University, 9(2), 1245-1261.

Boonyarattapan, M. (2015). Principles of Curriculum Development. Bangkok: Ramkhamhaeng Press.

Chantaranuwong, W. (2015). Guidelines for Developing the Thinking and Learning Skills of Learners. Bangkok: Klangnana Vitthaya Press.

Chaowakiratipong, N. (2016). How to Teach and Create Creative Thinking. Bangkok: Chulalongkorn University Press.

Creswell, J. W. (2008). Education research, planning, conducting, and evaluating qualitative and quantitative research (3rd ed.), Upper Saddle River, N.J.: Perason/Merill Prentice Hall.

Dillenbourg, P. (1999). What do you mean by 'collaborative learning'? In P. Dillenbourg (Ed.), Collaborative-learning: Cognitive and Computational Approaches (pp. 1-19). Oxford: Elsevier.

Edwards, M., McGoldrick, C., \& Oliver, M. (2006). Creativity and curricula in Higher Education: Academics' perspectives. In N. Jackson, M. Oliver, M. Shaw \& J. Wisdom (Eds.), Developing creativity in higher education: An imaginative curriculum (pp. 59-73). London: Routledge.

Eragamreddy, N. (2013). Teaching critical thinking skills. Instructional Journal of English Language Translation Studies, 1(2), 124-145.

Faculty of Education, Khon Kaen University. (2017). Bachelor of Education Program, Social Studies, 5-year course. Khon Kaen: Faculty of Education, Khon Kaen University.

Gerlach, V. S., \& Ely, D. P. (1980). Teaching and media: A systems approach. Englewood Cliffs, N.J.: Prentice-Hall, Inc.

Guilford, J. P. (1970). Traits of Creativity. In P. E. Vernon (Ed.), Creativity. Beltimore: Penguin Books.

Hawkins, J. (2001). The creative economy: How people make money from ideas. London: Allen Lane.

Ibikunle, N. A. (2006). Fundamentals of Educational Technology. Y Books Adesoye Crescent, Ibadan.

Johnson, D. W., Johnson, R. T., \& Holubec, E. J. (1994). The nuts and bolts of Cooperative Learning. Edina, Minnesota: Interaction Book Company.

Johnson, D. W., Johnson, R. T., \& Smith, K. A. (2006). Active learning: Cooperation in the university classroom (3rd ed.). Edina, MN: Interaction.

Kanchanachaya, N., Suwannatthachote, P., \& Suwanmonkma, S. (2013). How to enhance creative problem 
solving in instructional media production course: A finding from needs assessment. Academic Services Journal: Prince of Songkla University, 23(2), 192-206.

Khachornsart, R., \& Parkpian, P. (2017). Thailand-Laos educational cooperation after stepping into ASEAN in the case of twin schools under the Mekong River's Cultural Context. Mekong River Basin Education Research Institute, Office of Education Region 13.

Khaemmani, T. (2017). The Science of Teaching Knowledge to Organize an Effective Learning Process (21st ed.). Bangkok: Chulalongkorn University Press.

Lai, E. R. (2011). Motivation: A Literature Review. Pearson Research Report.

Mumford, M. D., Marks, M. A., Connelly, M. S., Zaccaro, S. J., \& Johnson, J. F. (1998). Domain-based scoring in divergent-thinking tests: Validation evidence in an occupational sample. Creativity Research Journal, 11(2), 151-163. https://doi.org/10.1207/s15326934crj1102_5

Munkham, S. (2004). Teaching strategies for creative thinking. Bangkok: Printmaking Limited Partnership.

Ofsted. (2009). Twenty Outstanding Primary Schools: Excelling against the Odds. Manchester: Ofsted.

Olufunke, O. M., \& Olusola, A. A. (2010). Production and use of instructional materials for language teaching. African Journal of Multidisciplinary Studies, 2(1), 97-103.

Omenge, O. R., \& Proscah, M. J. (2016). Understanding the utilization of instructional media in training health professionals. Journal of Nursing and Health Science, 5(3), 01-08.

Oshodi, M. O. (2014). Instruction of instructiona media. Unpublished Master's in Education Thesis. Lagos, Nigeria, Africa.

Owoh, T. (2016). Improvement of vocational education curriculum implementation through instructional materials production and utilization in upper basic education in Nigeria. Education and Training, 2(2), 84-87. https://doi.org/10.20448/journal.522/2016.2.2/522.2.84.87

Panya-sai, W. (2016). Creative thinking development model of undergraduate students, Faculty of Education, Uttaradit Rajabhat University. Social Sciences Journal, 4(2), May-August 2014.

Phan-manee, A. (1997). Creative Thinking and Learning. Bangkok: Grammy Reed Press.

Phan-manee, A. (2014). Train to Think, Think Creatively. Bangkok: Chulalongkorn University Press.

Reiter-Palmon, R., Mumford, M. D., \& Threlfall, K. V. (1998). Solving everyday problems creatively: The role of problem construction and personality type. Creativity Research Journals, 3, 187-197. https://doi.org/10.1207/s15326934crj1103_1

Ritter, S. M., Gu, X., Crijns, M., \& Biekens, P. (2020). Fostering students' creative thinking skills by means of a

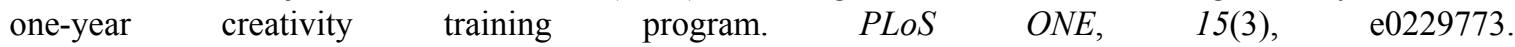
https://doi.org/10.1371/journal.pone.0229773

Ritter, S. M., \& Mostert, N. (2020). Enhancement of creative thinking skills using a cognitive-based creativity training. Journal of Cognitive Enhancement, 1(3), 243-253. https://doi.org/10.1007/s41465-016-0002-3

Robillos, R. J. (2020). Instruction of metacognitive strategies: Its role on EFL learners' listening achievement and awareness of their metacognitive listening strategies and self-regulation of learning. Asian EFL Journal, 27(3), 359-386.

Roger, C. R. (1970). Towards a Theory of Creativity. In P. E. Vernon (Ed.), Creativity. Beltimore: Penguin Books.

Runco, M. A. (1994). Problem finding, problem solving, and creativity. California: Greenwood Publishing Group

Runisah, H. T., \& Dahlan, J. A. (2016). The enhancement of students' creative thinking skills in Mathematics through the $5 \mathrm{E}$ learning cycle with metacognitive technique. International Journal of Education and Research, 4(7), 347-360.

Slavin. (1995). Cooperative Learning: Theory Research and Practice. Englewood Cliffs, N.J.: Prentice Hall.

Srisa-ard, B. (2010). Basic Research (8th ed.). Bangkok: Suveiriyasarn.

Sternberg, R. J., \& Lubart, T. I. (1999). The concept of creativity: Prospects and paradigms. In R. J. Sternberg (Ed.), Handbook of Creativity (pp. 3-15). Cambridge: Cambridge University Press. https://doi.org/10.1017/CBO9780511807916.003 
Suthirat, C. (2016). How to Teach and Create Creative Thinking. Bangkok: Chulalongkorn University Press.

Taba, H. (1962). Curriculum Development: Theory and Practice. New York: Harcourt Brace Jonvanovich.

Torrance, E. P., \& Myers, R. E. (1962). Creative Learning and Teaching. New York: Good, Mead and Company.

Tungkasamit, A. (2016). Social studies in the world of ASEAN. Khon Kaen: Faculty of Education, Khon Kaen University.

Ugwu, G. O. (2014). The perceived objectives of roadside mechanic apprenticeship programs in Mid-Western Nigeria. Australian Journal of Adult Learning, 44(1), 84-94.

UNESCO International Bureau of Education. (2014). Creativity. In Guiding Principles for Learning in the Twenty First Century (pp. 15-18). Retrieved from http://www.ecolint.ch/file/621/download?token=zhQHu7qg

Van Boxtel, C., Van der Linden, J., \& Kanselaar, G. (2000). Collaborative learning tasks and the elaboration of conceptual knowledge. Learning and Instruction, 10(4), 311-330. https://doi.org/10.1016/S0959-4752(00)00002-5

Wannapin, S. (2012). Creativity for Value Management. Bangkok: Kasetsart University Publishing.

Wisalaporn, P. et al. (2015). The Role of Education in Building ASEAN Community 2015. Retrieved from http://www.bicmoeg.th/images/stories/book/other/ASEAN/edbuilding/ASEANcommunity.pdf

Wongsupachainimit, A., Mano, K., \& Maunsaiyat, S. (2013). Engineering education student's opinion toward teaching professional at Faculty of Industrial Education, King Mongkut's Institute of Technology Ladkrabang. Journal of Industrial Education, 12(2), 103-109.

\section{Copyrights}

Copyright for this article is retained by the author, with first publication rights granted to the journal.

This is an open-access article distributed under the terms and conditions of the Creative Commons Attribution license (http://creativecommons.org/licenses/by/4.0/). 